\title{
Experiences with Virtual Learning
}

\section{Using 3D Interactive Systems for Education and Training}

\author{
Dr. Damian Schofield \\ Director of Human Computer Interaction, Department of Computer Science, \\ State University of New York (SUNY), Oswego, New York, USA \\ Adjunct Associate Professor, Edith Cowan University, Perth, Australia \\ schofield@cs.oswego.edu
}

\begin{abstract}
Advanced 3D virtual environment technology, similar to that used by the film and computer games industry can allow educational developers to rapidly create realistic 3D, virtual environments. This technology has been used to generate a range of interactive learning environments across a broad spectrum of industries and educational application areas.
\end{abstract}

Virtual Reality (VR) simulators represent a powerful tool for learning and teaching. The idea is not new. Flight simulators have been used for decades to train pilots for both commercial and military aviation. These systems have advanced to a point that they are integral to both the design and the operation of modern aircraft $[1,2]$. There are a number of lessons that can be learned from other industries that have successfully utilised virtual training and learning systems for a number of years. Generic rules of thumb regarding the specification, development, application and operation of these learning environments can be garnered from other industrial training systems and examined in an educational context $[3,4,5,6,7]$.

This paper will introduce a virtual learning environment which has been developed by the authors. During the implementation of this, and other, visual learning environments a number of complex operational problems have been encountered, these have required a number of innovative solutions and management procedures to be developed.

The paper will also discuss the implementation of these systems and extrapolate the lessons learnt into general guidelines to be considered for the development of VR based educational learning resources. These guidelines will then be discussed in the context of the development of ViRILE (Virtual Reality Interactive Learning Environment). This software is designed for use by undergraduate chemical engineers and simulates the configuration and operation of a polymerisation plant [4].

Keywords: learning; virtual reality; training; education; guidelines

\section{INTRODUCTION}

Inevitably the future will be digital. The continuing digital revolution has had an enormous impact on the way learning is undertaken and information is disseminated. A wide range of digital media will end up being used, to varying degrees in educational applications around the world. However, in many places around the globe technology can be slow to become fully accepted, this is often due to financial and budgetary constraints. It is fair to say that, in general, utilisation of digital learning media in many educational institutions can lag behind the technological development $[8,9,10,11,12]$.

Advanced 3D computer graphics and virtual environment technology, similar to that used by the film and computer games industry has been used to generate interactive learning environments that will allow learners to undertake a range of simulated experiences. Other 'virtual' teaching and training applications from a range of industries (flight, surgery and driving simulators to name a few) have proved the value of this technology, however these 3D virtual environments are currently not widely utilised in the education sector. Early attempts at 'virtual' training simulators, particularly those which tried to apply 3D computer graphics based technology, were often constrained by lack of realism detail in their graphical interfaces and crude level of simulation [8, 13, 14, 15]. However, it has been also noted that even given these limitations, these virtual environments had the potential to allow users to experience situations which would not readily exist within the real world, e.g. to see 'into' a chemical reaction or to cause a major catastrophe through their actions $[16,17$, $18,19]$.

Research and experience building a range of interactive, virtual reality based learning environments has demonstrated the enormous benefits of using this type of technology in an educational context, and has also highlighted a few of the potential problems $[3,10,11,15,20]$. This paper will introduce these issues with regard to the ViRILE system and discuss some of the potential conclusions and recommendations learnt from the system development and implementation.

\section{TECHNOLOGY}

It is important to realise that the use of such computergenerated, 3D interactive learning media in the education sector is only the current manifestation of a long history of visual training and education systems [13, 17, 21]. However, computer animations and interactive virtual simulations are unparalleled in their capabilities for presenting complex information. The use of such enabling visualisation technology can affect the manner in which data is assimilated and correlated by the viewer; in many instances, it can potentially help make the information more relevant and easier to understand [7, 16, 18, 21, 22]. 
At this point, it is perhaps appropriate to define and describe the technologies under discussion in this paper. Virtual Reality or 'VR' involves interactive, real-time, 3D graphical environments that respond to user input and action, such as moving around in the virtual world or operating virtual equipment. An important aspect of such a virtual reality system is its underlying processes, simulations, behaviour and reactions, and the way a user can interact with objects within the virtual world. A virtual reality user could, for example, sit in a virtual vehicle and drive it. Popular cultural examples of this technique include modern $3 \mathrm{D}$ computer games such as Unreal Tournament and Grand Theft Auto.

Many novel applications of this technology have emerged recently due to the rapid developments in personal computer technology, especially for desktop VR. In particular, the home computer games market has encouraged the development of software tools together with specialist $3 \mathrm{D}$ graphics accelerator boards and peripheral products. Whilst much of the development is aimed at the home and leisure industry, there are many applications that have been developed for a range of commercial sectors. This has consequently also had an effect on the education sector, and is partly one of the reasons for the technology being introduced into learning environments around the world over the past few years. These types of CG and VR display systems can offer major advantages over other visualisation media, because of the interactive nature of the experience they create $[17,22]$.

Second Life (SL) is a prime example of a multi-user 3D virtual environment that has been applied for online education by a number of educational institutions, to increase social interactions to deepen learning among users. It was developed and launched by Linden Labs in 2003. Second Life supports virtual learning with 3D learning spaces and a unique HumanComputer Interaction (HCI) style with the potential to promote a sense of 'presence' which engages users in the learning activities $[12,23,24]$.

\section{VIRTUAL REALITY INTERACTIVE LEARNING ENVIRONMENT (VIRILE)}

A problem identified by academic staff among a mining/mineral processing/chemical engineering cohort of students at the University of Nottingham in the UK was the students' lack of awareness about 'real' process equipment [4, 10]. Question and answer sessions indicated that the undergraduates were often not only unfamiliar with full-scale industrial plant, but were also unable to identify some of the main components even though they had been studied (theoretically) in the classroom. To address this issue a virtual environment was developed to replicate a 'real' industrial process. This allowed the students to experiment with largescale equipment to which they would not normally have access. It was decided to build a large scale virtual simulation where students are able to design a particular processing plant and then operate the major equipment. Key features of this project included the design orientated nature of the task facilitated by the interactive character of the technology $[10,20]$.

A continuous polymerisation plant was modelled, consisting of a reactor section and three distillation columns
(Fig. 1). It is important not to underestimate the work involved in developing commercial quality, virtual reality software based training simulators to a professional standard. To a generation weaned on animated movies and computer games, the level of expectation of the student cohort is high. Previous virtual learning environments developed have provided experience of the quality of the software required to gain a level of acceptance among the learners [20].

Massive amounts of process plant simulation data was generated using HYSIS (steady state chemical flowsheet simulation software - (C) AspenTech 2011). Individual items of the plant were defined in terms of their operational capabilities and properties. These plant models were then combined to produce a conceptual simulation model of a polymerization plant with the capability to handle the asset management, operational optimization, production planning and business forecasting. HYSYS integrates steady state and dynamic modeling capabilities and the plant model created could be simulated from either perspective based on a robust thermodynamic foundation. A large data base containing all the possible operating states of the chemical plant equipment was created using this HYSIS simulation model. This database consisted of a large series of text files storing the numerical results.

The virtual world was built using commercial threedimensional modeling software (3DS Max (C) Autodesk 2012). The models of the individual items of chemical equipment were assembled to generate an entire plan site and imported into a real-time rendering engine. The Shockwave 3D engines (C) Adobe 2012) was used to provide real time rendering of the scene, navigation capabilities, a physics engine and collision detection. An interface to allow the user to interact with the plant equipment was built in Director (C Adobe 2009)(Fig. 2).

A real time, mathematical model was programmed in $\mathrm{C}^{++}$ to reference the data generated by the HYSIS simulation model. The final learning environment contains over a billion discrete configurable states, allowing the students unlimited scope for experimentation and configuration. This also allows the educator to set individual tasks within the learning environment for particular students. A full economics and costing model has also been integrated into the simulation, giving learners an insight into the constraints facing engineers in the real world.

The ViRILE system is currently utilized as an integral component of the undergraduate Chemical Engineering degree program at the University of Nottingham in the UK. Each student on the program is assigned an individual task within the virile system (usually to economically produce a certain substance at a specified concentration). The students each have to purchase the equipment required for their own plant configuration and set up the operating conditions of the polymerization plant. Extensive testing of the ViRILE system among these students has been undertaken and the results have been published in other papers [25, 26]

The ViRILE system allows a student to easily understand complex material and interact with a detailed processing simulation. Most people would be positive about the benefits of the interactive environment used as an educational tool and 


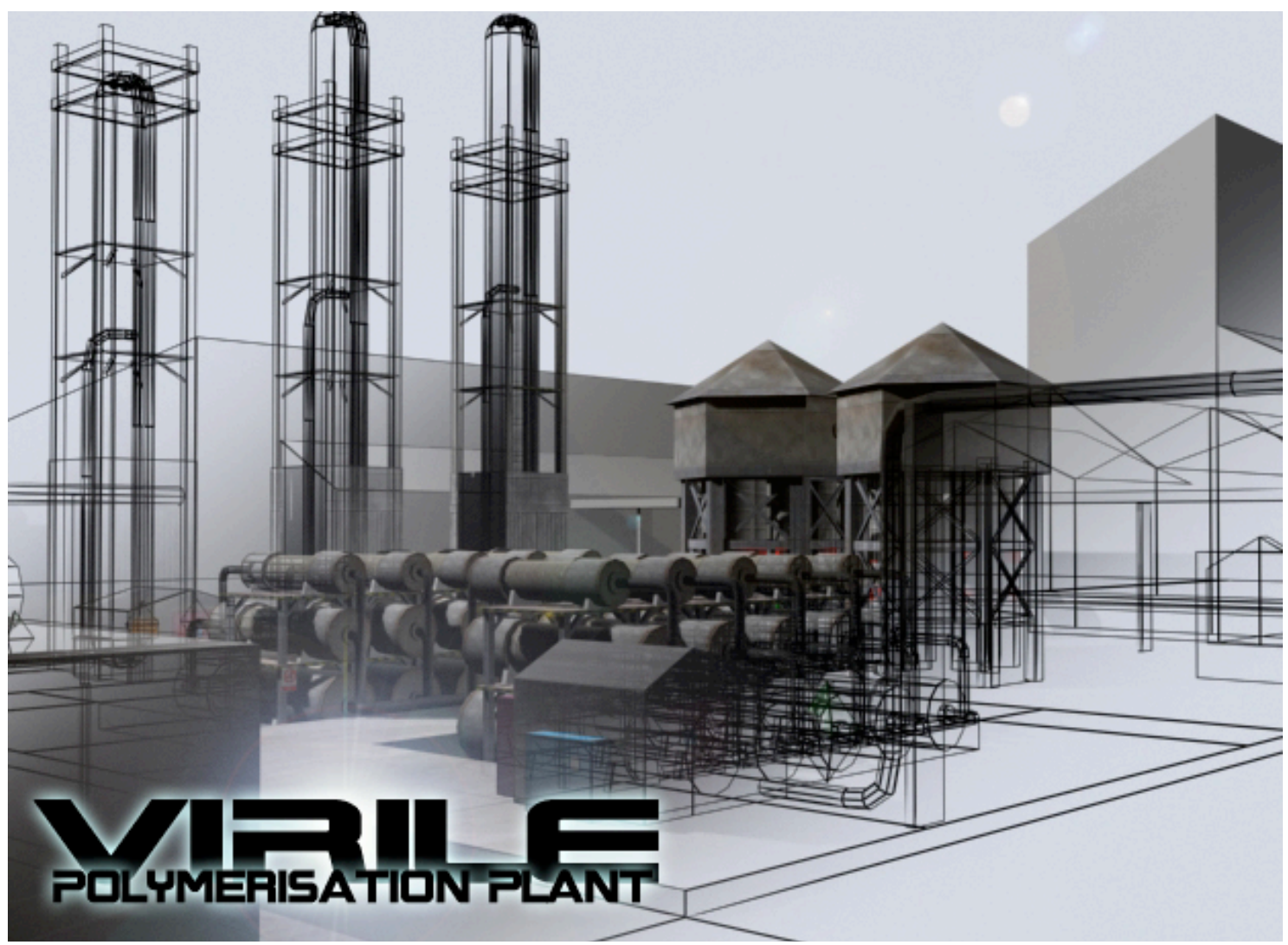

Figure 1. The Virtual Processing Plant

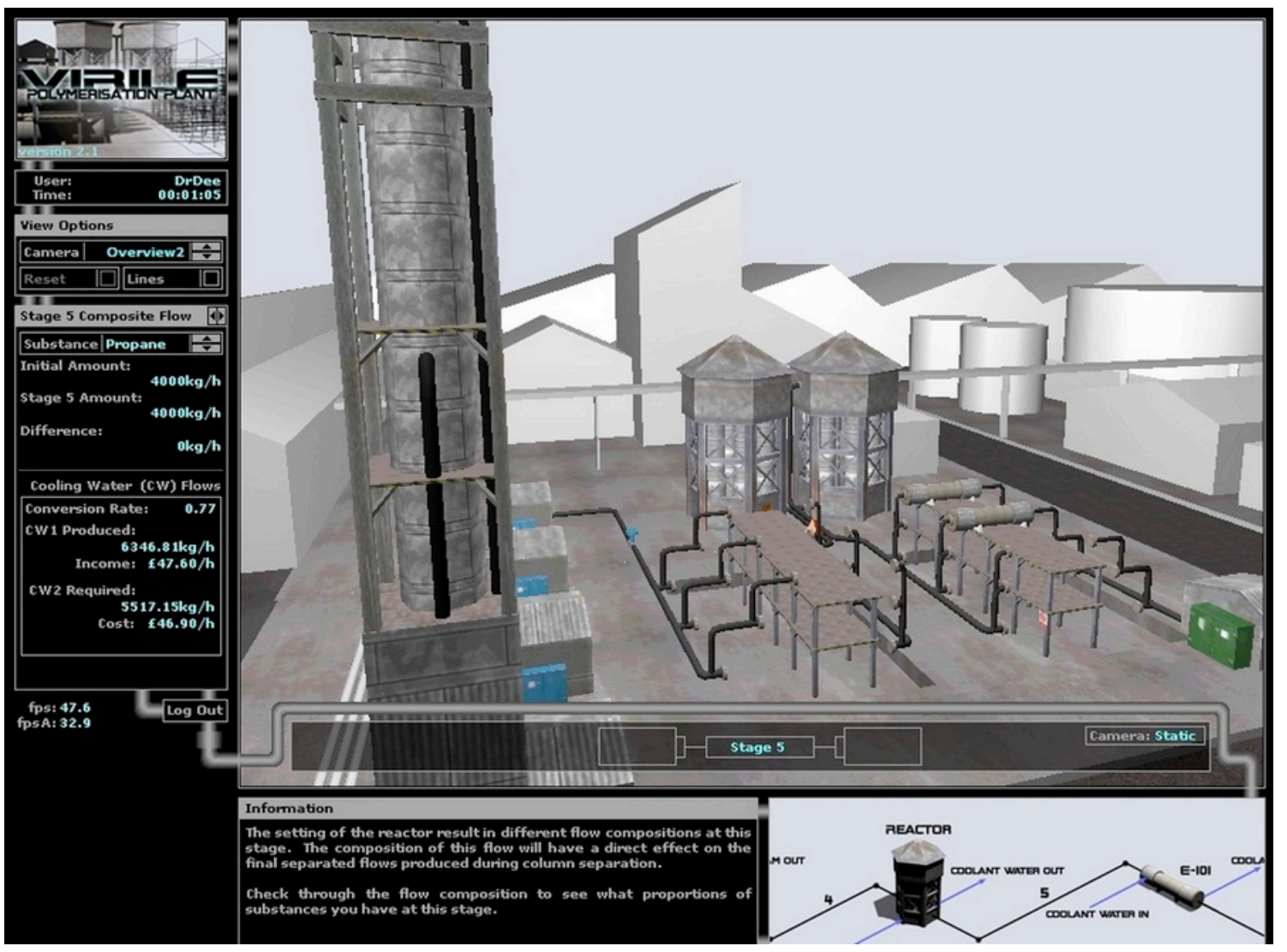

Figure 2. The ViRILE Graphical User Interface 
understand how such a simulation can help a student to understand the complex chemical processes involved. However, there are a number of issues and questions that appear when such a simulation model is examined in further detail $[17,27]$.

\section{ISSUES ARISING}

Analyses of 3D interactive learning environments show that they can be advantageous in many situations, providing they are used appropriately $[3,11,12,21,22,28]$. However, potential difficulties can occur from the application of this technology; when learning environments are examined in further detail, a number of issues and questions can arise. The consequences of these problems cannot be underestimated [29]. The following sections provide details of some of the more important and relatively common and issues and problems that can arise when using this technology.

\section{A. Viewpoint}

One issue is how to correlate the viewpoint of a user in a 'virtual' environment with the view from their physical position at the scene. For example, compare the "physical world' view of a worker on a real chemical plant with the field of view of a camera in the VIRILE system. Unlike the real world, in virtual worlds it is possible to rapidly switch between views of the chemical plant from multiple angles [4, 30, 31].

Popular computer game titles provide a good example of distinct viewing configurations through various game playing styles. Unreal Tournament belongs to a genre known as the First Person Shooter (FPS), distinguished by a first person perspective (egocentric) that renders the game world from the visual perspective of the player character. Grand Theft Auto is a Third Person Shooter (TPS), this is a genre of video game in which an avatar of the player character is seen at a distance from a number of different possible perspective angles (exocentric). In any virtual learning environment (as in any computer game), the choice of the viewing perspective may have a significant effect on the way an image is interpreted by the viewer. Changing the viewing perspective can potentially alter which 'character' in a learning scenario that a viewer identifies with, or aligns themselves with [32].

Film has a long history of different conventions to convey information. Camera angles may convey power or weakness for example. These are not arbitrary, the camera angles reflect real-life situations. The paraproxemic principle involves a sense of created intimacy with the viewers through point-ofview and camera angles [17,32].

When we move around in an unfamiliar environment, we often use exocentric information such as a road map or a carnavigation system to help to findi our way based on this realtime egocentric virtual environment. It has been shown that concurrent exocentric information can improve learning performance in virtual worlds. This suggests that we create a common representation of a learning environment as a working memory for navigation.

While the enhanced interface might give people greater confidence that they understand the virtual world they are in, viewing an exocentric view of the world could diminish the realism of their experience or their sense of being immersed in a world. The user's sense of immersion often depends on the extent to which the centers of their egos overlap the virtual ego center projected in the egocentric view. The addition of exocentric views may diminish this overlap. More research required on the impact of these types of technologies on the learning process.

There is also an issue regarding the correlation of the locations of learners when they are positioned in a virtual environment, such as ViRILE, in comparison to actual positions on a real chemical plant. It is a reasonable assumption to make that most people would be better able to correlate their actual spatial location from a 3D 'virtual' simulation, than they might be able to on a 2D plan or map. It is interesting to note that research has indeed shown that a significant proportion of the general public has problems relating and correlating 2D (e.g. maps and plans) and 3D (e.g. real and virtual) spatial information [33]. In practice, this means that some learners may find it easier to their physical position by referring to a virtual environment (relating physical 3D to 'virtual' 3D) rather than on a $2 \mathrm{D}$ plan or map of the scene.

Virtual environments can improve learning performance by exploiting the powerful human capabilities for spatial cognition. This opportunity has been demonstrated by many prior experiments $[1,5,7,13]$. It is tempting to believe that providing greater spatial flexibility-by moving from flat $2 \mathrm{D}$ to 3D user interfaces-will further enhance user performance. Subjective measures can reinforce the performance measures, and research has indicated that users found interfaces with higher dimensions more 'cluttered' and less efficient $[11,13]$.

Many educational applications of virtual environments require people to be able to transfer spatial knowledge acquired in a virtual world to a real-world situation. Short periods of learning were no more effective than other alternative pedagogical forms. However with sufficient exposure to the virtual training environment, the virtual world learning usually surpasses real-world training $[3,7,11,13,20]$.

One of the main advantages of the use of an interactive 'real-time' virtual simulation, such as ViRILE, over a passive computer-generated animation is the ability to dynamically control the virtual camera movement within the environment $[31,34]$. This permits the user to 'interactively' adjust the view of the digital object - for example, a user could move a camera around the chemical plant until the virtual view matches their memory of their view of an incident or event. However, it should be noted that how humans position themselves and correlate spatial information between the 3D views of the virtual world and the physical world are not fully understood $[35,36]$.

\section{B. Realism}

The environment surrounding any particular scene that is to be reconstructed may be included within the learning environment. For example, a ViRILE model not only shows the location of the main items of chemical plant, but also the position of nearby buildings and other environment features. These items may be placed and animated within a chronology 
of events or a time frame. As technology develops, the realism of virtual environments continues to improve. As computerprocessing power increases and software tools develop, it is natural to assume that it will be possible to achieve a similar level of realism within the computer-generated environments used in learning environments. Two recent, popular films demonstrate two distinct animation and representation styles. The first, Brave (C) Pixar Studios, 2012) relies on a cartoonlike, abstract approach to present its narrative. The second, Avatar (C) $20^{\text {th }}$ Century Fox, 2009) relies on a more realistic representational form. A number of researchers have noted an interesting observable fact relating to the realism in such animated imagery, where many viewers become 'unnerved' by images of humans which are close to, but not quite real. This phenomenon (experienced by a number of viewers of the Avatar movie) has become known as the 'uncanny valley', because of the sharp dip seen in a graph of familiarity against the perception of reality [37].

Objects in a virtual learning environment can be modeled with varying degrees of accuracy to explain and visualise the certainty, believability and veracity of the information related to that object. For example, in the ViRILE system, the colour of particular items of plant varied based on the temperatures of liquids flowing through the equipment at any particular moment during the life of the simulation. However, this mixing of visual metaphors and modes may be potentially disorientating to some viewers $[17,38]$. Combining abstract data representations in photo-realistic environments may provide an unnatural experience for the viewer. A number of researchers have reported on the way viewers can be misled by the use of visual metaphors and abstract representations in learning environments [38, 39, 40, 41].

The mixing of levels of detail and modes of abstraction may be potentially disorientating to some viewers. Combining different degrees of photorealism and expecting the viewer to draw additional information from a number of abstract representations in the virtual environment may overload the viewer and potentially add to their confusion rather than increasing their comprehension of the information that is presented (Fig. 3). In a virtual learning context, many systems currently in use rely on fairly abstract representations [20,42]. However, as technology progresses, the development of increasingly photorealistic learning environments becomes an ever more likely [29, 43].

\section{Media Mode}

It is rare that one form of media will be sufficient to fully explain every facet of a complex process or case to a viewer. Many people see 3D technology as a universal solution, and it can be 'over-applied' or 'misapplied' in many learning applications [13, 17]. It is important to choose an appropriate representation mode (photographs, text, video, graphics etc.) for the material that needs to be presented. Additional data may be included and displayed within any virtual environment; within the ViRILE system location based statistical or analytical data could be displayed and calculated experimental results could be presented in a visual format, all linked from 3D virtual chemical plant objects.

The linking of 'real' evidence to spatially contextualised hotspots in a virtual environment has the potential to provide an effective mechanism to help the viewer understand the spatial relationship of the evidence. Such a multi-modal approach can be very effective, and different media may also be used as a device to help to retain the attention of the learner and thereby increase understanding $[13,44]$.

\section{Audio}

The integration of physical-world audio evidence with learning environments has been used for many years. Spatialised audio rendering systems capable of rendering a number of dynamically moving sound sources in multispeaker, immersive, virtual environments, are possible using off-the-shelf audio hardware and software. Based on simplified physics-based models, developers can achieve a good trade-off between audio quality, spatial precision, and performance in any virtual environment $[45,46]$. Within the ViRILE system, spatially contextualized audio allowed the user could hear whether equipment was operating.

Research suggests that adding audio to a computergenerated visual can have a significant effect on the level of engagement of the viewer, and hence may potentially affect their understanding and interpretation of the evidence viewed $[47,48]$.
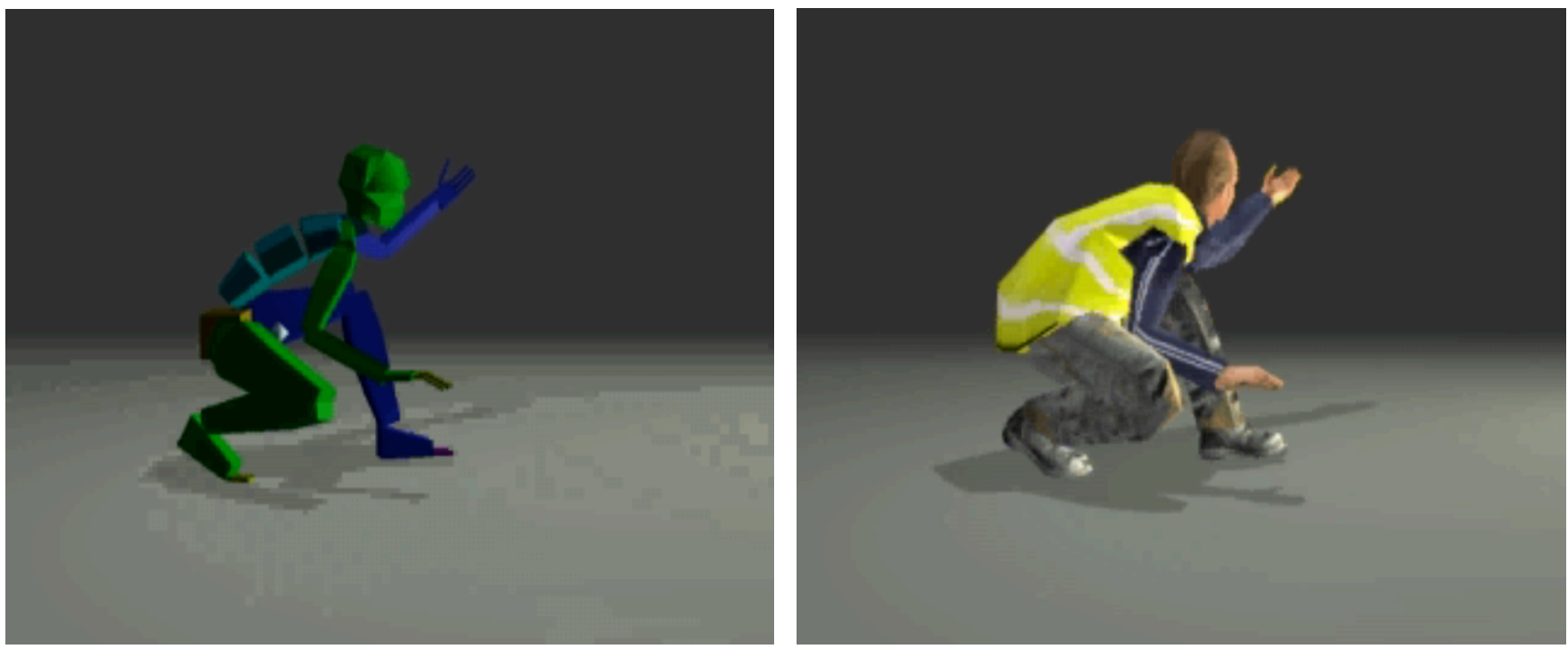

Figure 3. Demonstrating Varying Levels of Realism in the Representation of a Virtual Worker 


\section{E. Resolution}

One difficulty is to correlate the resolution of a virtual scene with that subjectively perceived by the viewer in the physical world. In this instance, resolution not only refers to screen image dimensions (the pixel count), but also to the level of photorealism of the virtual environment that is created [43, 49]. This also relates to the display mechanisms used, a viewer interacting with a learning environment on a mobile device such as a mobile telephone or an iPod has a very different experience to one who watches it on a cinema screen. In addition, a viewer watching a computer monitor or screen may not have the same experience (depth of field, motion parallax, peripheral vision etc) as a viewer watching a real event.

The ViRILE system was primarily designed to be used on a computer monitor, although tests were also undertaken using projected images on large scale screens. A relevant factor which needs to be considered is the way the technology is to be used (in what educational context), and for what purpose [3, $13,43,50]$.

\section{F. Accuracy}

The creation of any virtual environment begins with data collection; accuracy is crucial, because this data serves as the foundation for the environment created. The technology used for collecting data and measurements vary depending on the type of environment created. The ViRILE system was based on both manufacturers equipment specifications and measurements taken on site from real chemical plants. These measurements provided a reliable numerical data set for the creation of the geometry that is the foundation of any credible computer model or reconstruction of a scene. If the virtual environment is created to a sufficient level of accuracy, then it may potentially be used to test hypotheses, such as to verify the orientation or placement of specific equipment within the plant $[10,17]$.

\section{G. Simulation}

It should never be forgotten that a virtual simulation, is by its very definition a 'simulation' of reality. In the context of a learning environment, it is necessary to understand the nature of the simulation and the veracity of the representation, i.e. how close is it to the original evidence from which it was derived.

The behavior of the chemical plant within the ViRILE system simulation was based on the same equations as used by a chemical engineer calculating or predicting how the plant would behave under any particular set of conditions. However, questions that arise include whether the simulation applies the equations and formulae in the same way; whether the simulation works to the same level of accuracy; whether the simulation make the same assumptions as the chemical engineer, and whether the visual representation of the chemical plant in the virtual environment provides a realistic and relevant portrayal of the simulation data.

\section{H. Narrative}

The ability to move through time and along a chronology of events in the virtual environment may be potentially disorientating to many viewers. Most members of the general public are used to linear narratives, and may struggle to follow multiple narrative threads when faced with such a non-linear approach [51].

\section{Lighting}

Consideration needs to be taken into account as to how it is possible to correlate the lighting in the virtual world with that available at the real environment. It has to be determined whether an approximation is acceptable. Arguably, this might not be crucial in some simulations, so long as all objects are sufficiently illuminated so as to be clearly visible [52].

\section{RECOMMENDATIONS}

By their very nature, any recommendations and guidelines formulated are likely to be broadly defined and generic. They cover a range of topics related but not explicitly correlated with the issues discussed above. Many of the recommendations offered below are little more than general (common sense) suggestions that users of the technology be aware of these issues when involved in developing the types of 3D interactive learning simulations described in this paper.

\section{A. Field of View}

Designers of virtual environments ought to study filmmaking techniques for two reasons. First, to aim to achieve the same effects as a film-maker; perhaps getting the viewer to emotively identify with a particular character in a learning environment to enhance the power of the message. Alternatively, an animator or modeller may wish to eliminate these effects and to remove the emotive content to provide an objective, understandable view of a data set, with no distracting emotive attachment. An awareness of the ways the viewer can be manipulated (for example through the use of egocentric and exocentric viewpoints) is essential.

\section{B. Interaction and Resolution}

Careful thought needs to be given to the enabling technology; it is necessary to know how the user will interact with any virtual simulation created. For example, the best mechanism to teach a specific learning objective could be to deliver a spatially contextualised data visualisation to a user's Personal Digital Assistant (PDA) or mobile telephone screen as they traverse a real environment (such as a chemical plant). Alternatively, a complex data set may be best viewed as a shared experience on a large screen in a classroom environment.

\section{Modes of Representation}

Developers need to be aware that interactive 3D virtual reconstructions are not a panacea solution to all learning requirements. They are not ideal for representing every case. Any developer should adopt a holistic, multi-modal visualisation approach using appropriate technology (whether that is text, photography, video, computer graphics etc.) for the particular type of material and learning content. 


\section{Effect of the Media}

Most interactive 3D virtual environments have the capacity to allow the user to interact with a range of digital media (often using spatially, context sensitive hotspots - which usually consist of clickable links connecting objects in the virtual world to other media such as text, photographs and video). It is necessary to be not only aware of the effect of the particular form of media used, but also to have an appreciation of the context in which it will be experienced by the user. The pedagogical effect of transitions between the forms of media should be considered. For example, switching between a virtual, rendered image of a chemical plant and a real chemical plant photograph may cause confusion in the learner as they attempt to correlate information between the different media forms and levels of detail.

\section{E. Audio}

The integration of sound into the virtual world is often overlooked or added as an afterthought. Very few virtual developers are also qualified as, or competent at, being sound engineers. Effective audio soundtracks can add new dimensions to the learner's media experience.

\section{F. Abstraction}

Careful use of visual metaphors is essential. Thought needs to be given to each abstract data representation in the environment and how that will be perceived by the potential audience. Experience and literature from disciplines such as psychology, cultural and critical theory, visual media, art history, education and such like can inform how abstract (and realist) representations are interpreted by the viewer. This in turn affect information that the viewer remembers and understands from the visual simulation presented to them.

\section{G. Navigation and Interface}

Many interactive virtual simulations have complicated navigation systems (often based on computer game style controls) which may add an extra layer of complexity to the data the user is trying to comprehend, rather than augmenting their understanding. Careful thought should be given to the options available to the user. If control is to be passed to the viewer, then it may be better to restrict their movement and control in the virtual environment (for example between set points) rather than allow them to potentially become 'lost' in the data or environment. The ability to professionally manipulate, operate and utilise the technology needed to navigate through complex $3 \mathrm{D}$ data sets is a skill that many members of the general public do not possess.

\section{H. Behaviour}

It is important that the developers of virtual environments have an understanding of the processes and events being simulated (whether this is a chemical plant, vehicle movement or human anatomy). The developers must be aware of the veracity and realism of the simulation, i.e. the accuracy of the model. Also, it is important that if decisions are to be made based on the simulation, it is necessary that information is made available that explains how the simulation works (at a range of levels) to the learner.

\section{Narrative}

In an interactive simulation, the user may often take control of the narrative, altering the chronological presentation of information, and choosing which information they see at which time. This can easily become confusing to the user, particularly to those used to linear narratives in other media (for example, novels and films). Developers should provide a guide to the interactions within their learning environments and be aware of how the users are able to interact with the chronology of the data and any possible interpretations that may result.

\section{J. Lighting}

It is very rare that light meters would be installed in a real world location, measuring the intensity of the illumination at a particular moment, thus allowing the designer of a virtual world to replicate exactly the luminosity in the virtual environment. In many cases, it is possible to argue that this is not an issue, because the lighting may not be crucial to the viewing of the information. However, considering the amount of money and time spent in a major motion picture on lighting and the effect it can have on the viewer, one can see how the effect of the virtual lighting might be significant, and perhaps more consideration should be given to this aspect of development.

\section{K. Testing}

It is axiomatic that a simulation should be tested before it is released. However, it is common knowledge that a number of broadly distributed learning environments have received limited user testing before their release [3]. The use of this type of technology requires perceptive construction, because a number of issues only come to light when the technology makes contact with the users. For example, the brightness may be too low, or the colours on the image that is projected may be different to how they appeared on a small monitor, or the resolution of the display may make some objects difficult to see. As with any technology, it is important to be aware that it has the potential to fail. A back-up plan must always be in place.

\section{SUMMARY}

Computer graphics technology advances rapidly and the public, who regularly see photo-realistic computer graphics on television, expect to see their TV experience duplicated in the workplace and specifically in the modern day training and educational tools they use. Learners expect professional visual representations illustrating complex information, polished digital media displays demonstrating the location of spatially distributed data and dynamic animated graphics showing event chronologies.

Our culture is dominated with images whose value may be simultaneously over-determined and indeterminate, whose layers of significance can only be teased apart with difficulty. Different academic disciplines (including critical theory, psychology, education, media studies, art history, semiotics 
etc.) help explain how audiences interpret visual imagery. However, the analysis of training imagery and its interpretation by learners is often overlooked [53].

Around the world a number of educational organisations are already beginning to utilise 'slick' visuals to replace oral/text based learning materials and depend on their audience adapting a visual learning style. Whether one likes it or not, in the future the 3D interactive technology used to generate computer games is going to be increasingly used to generate graphical educational materials in a number of countries around the world. It is imperative that researchers and practitioners start to examine the implications of this technology, evaluate its potential advantages and disadvantages and assess its impact on the learners.

This paper has, hopefully, been fairly positive about the future and the benefits that can arise through the introduction of this technology into the education sector. However, there are a number of issues and concerns that arise through the use of 3D interactive virtual learning environments. These are not reasons in themselves for abandoning the use of this technology, but rather aspects that need to be investigated further and safeguards and guidelines put in place to avoid any possible misuse of this technology.

\section{REFERENCES}

[1] R. J. Adams, D. Klowden and B. Hannaford, "Virtual training for a manual assembly task", Haptics-e, vol 2, no 2, pp. 1-7, 2001.

[2] Sung, Y. H., Moon, Y. H. and Ha, S. W., Development of a Robot Flight-Simulator Education Programming System for Beginners Based on Web 2.0 - ARFLIS, Proceedings of Conference on the Education Technology and Training, 2009. ETT '09. Second International, pp 1015, 2009.

[3] J. Tromp and D. Schofield, "Practical experiences of building virtual reality systems", Proceedings of Designing and Evaluating Virtual Reality Systems Symposium, University of Nottingham, UK, January 2004.

[4] D. Schofield, E. Lester and J. A. Wilson, "ViRILE: Virtual reality interactive laboratory experiments", Proceedings of Innovation, Good Practice and Research in Engineering Education Conference, Wolverhampton, UK, June 2004.

[5] D. Schofield, "Do you learn more when your life is in danger? New technologies for safety training", Proceedings of the Conference on Virtual Reality in Training, Pittsburgh, U.S.A., July 2006.

[6] McGlinn, K., Brennan, R., O'Sullivan, D. and Lewis, D., The SimCon Generator: An interactive context simulator for rapid evaluation of Smart Building Applications using Virtual Reality, 2011 IEEE International Conference on Pervasive Computing and Communications Workshops (PERCOM Workshops), pp 50-55, 2011.

[7] Schwaitzberg, S. D., Godinez, C., Kavic, S. M., Sutton, E., Worthington, R. B., Colburn, B. and Park, A., Training and Working in High-Stakes Environments: Lessons Learned and Problems Shared by Aviators and Surgeons, Surgical innovation, vol 16, no 2, pp 187-195, 2009.

[8] M. Roussos, A. E. Johnson, J. Leigh, C. A. Vasilakis, C. R. Barnes and T. G. Moher, NICE: Combining constructionism, narrative, and collaboration in a virtual learning environment, Computer Graphics, (ACM SIGGRAPH), vol 31, no 3, pp. 62-63, 1997.

[9] D. Schofield, J. Noond and A. Burton, "Reconstructing accidents: simulating accidents using virtual reality", Proceedings of APCOM XXX Symposium 2002, Phoenix, Arizona, February 2002.

[10] E. Lester, D. Schofield and P. Chapman, "The interaction of engineering 'types': A study of group dynamics and its relationship to self and peer assessment during computer-based exercises". Engineering Education:
The Journal of the Higher Education Academy Engineering Subject Centre, Vol 1, No 1, pp. 39-49, 2006.

[11] Hamalainen, R., Designing and evaluating collaboration in a virtual game environment for vocational learning, Computers \& Education, vol 50, no 1, Pages 98-109, 2008.

[12] Warburton, S., Second Life in higher education: Assessing the potential for and the barriers to deploying virtual worlds in learning and teaching, British Journal of Educational Technology, vol 40, no 3, pp 414-426, 2009

[13] Wang, Q., Designing a web-based constructivist learning environment, Interactive Learning Environments, vol 17, no 1, pp 1-13, 2009

[14] B. Denby and D. Schofield, "The role of virtual reality in the safety training of mine personnel", Mining Engineering, October 1999, pp. 5964, 1999.

[15] Gijbels, D. and Loyens, S. M. M., Understanding the effects of constructivist learning environments: introducing a multi-directional approach, Instructional Science, vol 36, no 5-6, pp 351-357, 2008.

[16] D. Schofield, B. Denby and R. Hollands, "Safety in the twenty-first century: The application of computer graphics and virtual reality", in Mine Health and Safety Management, M. Karmis Ed, Littleton : SME, pp. 153-174, 2001

[17] D. Schofield, "Animating and interacting with graphical evidence: Bringing courtrooms to life with virtual reconstructions", Proceedings of IEEE Conference on Computer Graphics, Imaging and Visualisation 2007, pp 321-328, Bangkok, Thailand, August 2007.

[18] Hofstede, G. J., de Caluwé, L. and Peters, V., Why Simulation Games Work-In Search of the Active Substance: A Synthesis, Simulation Gaming, vol 41, no. 6, pp. 824-843, 2010.

[19] Peters, S., Bratt, E. and Kirschenbaum, S., Automated Support for Learning in Simulation: Intelligent Tutoring of Shiphandling, Proceedings of the Interservice/Industry Training, Simulation \& Education Conference (I/ITSEC), 2011.

[20] D. Schofield, E. Lester and J. A. Wilson, "Virtual reality based, interactive E-learning for chemical engineers", The 7th World Congress of Chemical Engineering, Glasgow, UK, July 2005.

[21] M. Roussos, A. Johnson, T. Moher, J. Leigh, C. A. Vasilakis and C. Barnes, "Learning and building together in an immersive virtual world, presence, vol 8, no 3, pp 247-263, 1999.

[22] Piccoli, G., Ahmad, R. and Ives, B., Web-Based Virtual Learning Environments, Management Information Systems Quarterly, 25(4): 401426, 2001.

[23] A. De Lucia, R. Francese, I. Passero and G. Tortora, "Development and evaluation of a virtual campus on Second Life: The case of secondDMI, Computers and Education, vol 52, no 1, pp. 220-233, 2008.

[24] L. Jarmon, T. Traphagan, M. Mayrath and A. Trivedi, "Virtual world teaching, experiential learning, and assessment: An interdisciplinary communication course in Second Life, Computers and Education, vol 53, no 1, pp. 169-182, 2009.

[25] Lester, E., Schofield, D. and Chapman, P., Self and Peer Assessment and Dominance during Small Group Work using Online Visual Tools, Seminar.Net - International Journal of Media, Technology and Lifelong Learning, vol 6, no 1, 2010

[26] Schofield, D. And Lester, E., Learning in a Virtual Environments Should there be Guidelines?, Proceedings of the World Conference on Educational Multimedia, Hypermedia and Telecommunications (EdMedia), Toronto, Canada, 28th June - 2nd July 2010.

[27] Corderoy, R. M. and Cooper, P., The Development of an Online Problem Based Learning Environment to Support the Development of Engineering Professional Practice Skills: The Virtual Engineering Consultancy Company (VECC), Indian Journal of Open Learning, Vol 9, No 3, 2000.

[28] Stoop, J. and Dekker, S., Accident modelling: from symptom to system, Proceedings of Human Factors : A System view of Human, Technology and Organisation, pp. 185-198, 2010.

[29] Schofield, D., Playing with Evidence: Using Video Games in the Courtroom, Journal of Entertainment Computing, vol 2, no 1 (Special Issue: Video Games as Research Instruments), pp 47-58, 2011. 
[30] J. Noond, D. Schofield, J. March and M. Evison, "Visualising the scene: Computer graphics and evidence presentation", Science and Justice, vol 42, no 2, pp. 89-95, 2002.

[31] Burelli, P. and Yannakakis, G. N., Towards Adaptive Virtual Camera Control in Computer Games, Smart Graphics: Lecture Notes in Computer Science, vol 6815, pp. 25-36, 2011.

[32] J. Bryce and J. Rutter, "Spectacle of the deathmatch: Character and narrative in first-person shooters", in ScreenPlay: Cinema/Videogames/Interfaces, G. King and T. Krzywinska Eds, pp. 66-80, 2002.

[33] M. A. Schnabel and T. Kvan, "Spatial understanding in immersive environments", International Journal of Architectural Computing, vol 1, no 4, pp. 435-448, 2003..

[34] Lipski, C., Linz, C., Berger, K., Sellent, A. and Magnor, M., Virtual Video Camera: Image-Based Viewpoint Navigation Through Space and Time, Computer Graphics Forum, vol 29, no 8, pp. 2555-2568, 2010.

[35] E. J. Arthur, P. A. Hancock and S. T. Crysler, "The perception of spatial layout in real and virtual worlds", Ergonomics, vol 40, no 1, pp. 69-77, 1997.

[36] D. R. Montello, M. Hegarty, A. E. Richardson and D. Waller, "Spatial memory of real environments, virtual environments and maps", in Human Spatial Memory: Remembering Where, G. L. Allen Ed, pp. 251286, 2004.

[37] K. F. MacDorman, "Subjective ratings of robot vdeo clips for human likeness, familiarity, and eeriness: An exploration of the uncanny valley", Proceedings of the ICCS/CogSci-2006 Long Symposium: Toward Social Mechanisms of Android Science, pp. 26-29, 2006.

[38] B. S. Fielder, "Are your eyes deceiving you? The evidential crisis regarding the admissibility of computer-generated evidence, N.Y.L. Sch. L. Rev., vol 48, no 1 \& 2, pp. 295-321, 2003.

[39] Sanchez-Vives, M. V. and Slater, M., From presence to consciousness through virtual reality, Nature Reviews Neuroscience 6, pp. 332-339, 2005.

[40] K. E. Bystrom, W. Barfield and C. A. Hendrix, "A conceptual model of the sense of presence in virtual environments", Presence, vol 8, no 2, pp. 241-244, 1999.

[41] Baker, T. E. and Holroyd, C. B., Which Way Do I Go? Neural Activation in Response to Feedback and Spatial Processing in a Virtual T-Maze, Cerebal Cortex, vol 19, no 8, pp. 1708-1722, 2009.
[42] Kosecka, J., Dellaert, F., Pollefeys, M. and Frahm, J., Virtual Representations and Modeling of Large-scale environments, Computer Vision and Image Understanding, vol 116, no 1, 2012.

[43] Jensen, H., Akenine-Möller, T. and Ryan, M., The race for real-time photorealism, American Scientist, vol 98, no 2, pp. 132-139, 2010.

[44] S. Ravet and M. Layte, "Technology-based training: A comprehensive guide to choosing, implementing, managing, and developing new technologies in training", Houston, TX : Gulf Publishing Company, 1998.

[45] Ketelhut, D. J., Nelson, B. C., Clarke, J. and Dede, C., A multi-user virtual environment for building and assessing higher order inquiry skills in science, British Journal of Educational Technology, vol 41, no 1, pp. 56-68, 2010.

[46] E. Frecon and M. Stenius, "DIVE: A scaleable network architecture for distributed virtual environments, Distributed Systems Engineering, vol 5, pp. 91-100, 1998

[47] Edirisingha, P., Nie, M., Pluciennik, M. and Young, R., Socialisation for learning at a distance in a 3-D multi-user virtual environment, British Journal of Educational Technology, vol 40, no 3, pp. 458-479, 2009.

[48] N. Tsingos, E. Gallo and G. Drettakis, "Perceptual audio rendering of complex virtual environments", Proceedings of the International Conference on Computer Graphics and Interactive Techniques, ACM SIGGRAPH 2004, pp. 249 - 258, 2004.

[49] F. P. Brooks, "What's real about virtual reality? IEEE Computer Graphics and Applications, vol 19, no 6, pp. 16 - 27, 1999.

[50] Dreher, C., Reiners, T., Dreher, N. and Dreher, H., Virtual Worlds as a Context Suited for Information Systems Education: Discussion of Pedagogical Experience and Curriculum Design with Reference to Second Life, Journal of Information Systems Education, vol 20, no 2, pp. 211-224, 2009.

[51] M. Craven, I. Taylor, A. Drozd, J. Purbrick, C. Greenhalgh, S. Benford, M. Fraser, J. Bowers, K. Jaa-Aro, B. Lintermann and M. Hoch, "Exploiting interactivity, influence, space and time to explore non-linear drama in virtual worlds, Proceedings of the SIGCHI Conference on Human Factors in Computing Systems, pp. 30-37, 2001.

[52] Löffler, A., Marsalek, L., Hoffmann, H. and Slusallek, H., Realistic Lighting Simulation for Interactive VR Applications, Proceedings of the Joint Virtual Reality Conference, JVRC11, 2011

[53] C. Spiesel, "Reflections on reading: words and pictures and law, International Journal of Law in Context, vol 2, no 3, pp. 305-320, 2006. 